\section{A child in time}

Portrait of the Artist as a Child: The Gravettian Human Skeleton from the Abrigo do Lagar Velho and its Archeological Context edited by João Zilhão \& Erik Trinkaus Instituto Português de Arqueologia: 2003. 610 pp. €40; distributed by Oxbow Books, $\mathfrak{E 3 5}, \$ 65$

\section{Paul Bahn}

The discovery in Portugal of the 'Lapedo child' in December 1998 was an important event for those studying European prehistory. For a start, this was the first Ice Age burial ever discovered in the Iberian Peninsula. Second, the skeleton was largely intact, although it had been disturbed by a bulldozer about ten years ago. Third, it was excavated with the most meticulous and exemplary care by Cidália Duarte and others. And finally, the child quickly became famous, even notorious, around the world because of claims that it might be a hybrid of Neanderthals and Cro-Magnons.

Portrait of the Artist as a Child is a fine monograph, beautifully produced in English, that presents scholars with a huge quantity of basic data. The first 200 pages cover the archaeological context of the burial. Although the human remains themselves could not be dated, the animal bones and charcoal found with them place the burial firmly at between 24,000 and 25,000 years ago, in the Gravettian period.

There is evidence that a shallow pit was

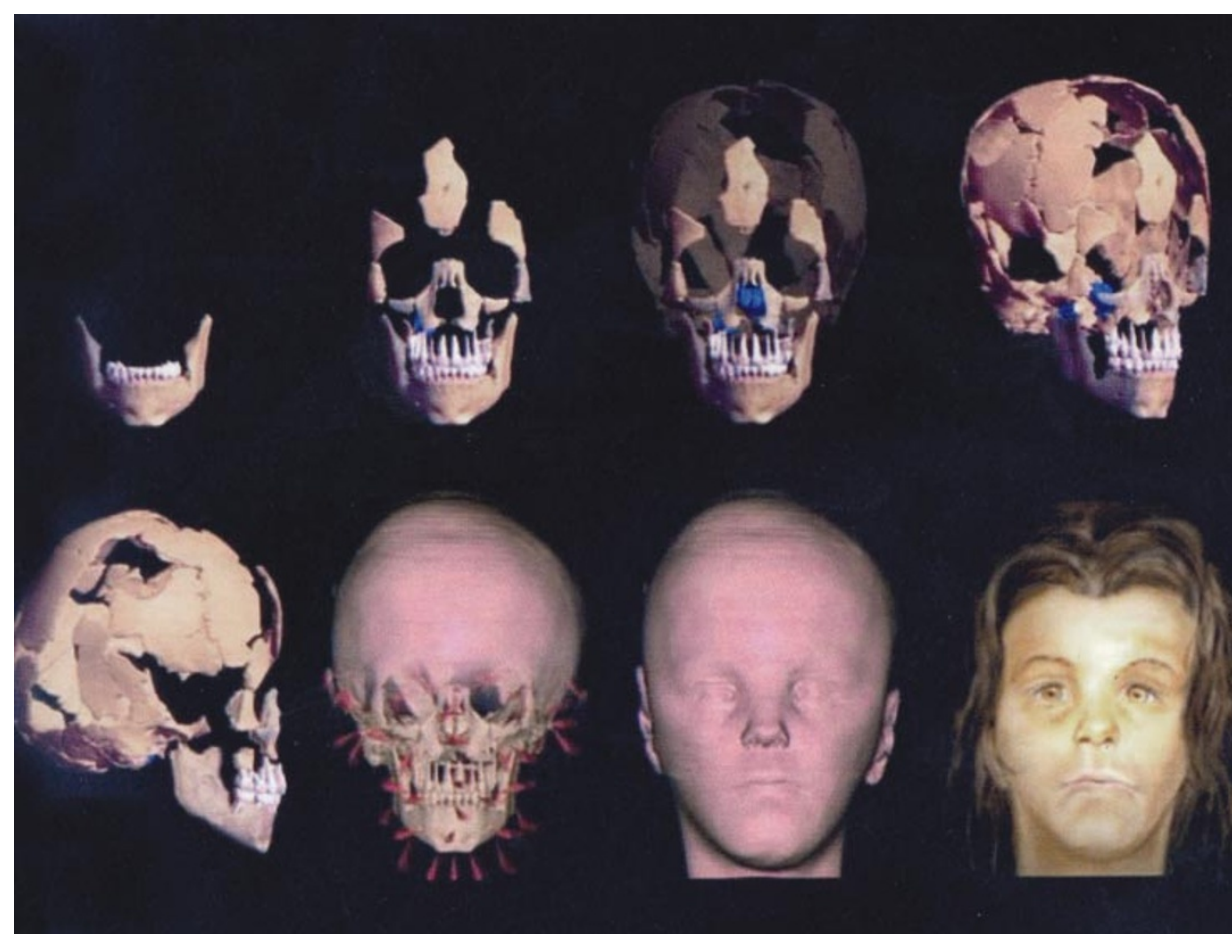

Adding flesh to the bones: studies of the Lapedo child's skull reveal both Neanderthal and Cro-Magnon features. dug in the back wall of a rock shelter and a branch of Scots pine was burned at the bottom. The child was then placed in the pit. Red-ochre stains on both the upper and lower surfaces of the bones, and a clear boundary with the surrounding whitish sediment, suggest strongly that the body was wrapped in an ochre-painted shroud. It lay in an extended position, with a young dead rabbit placed across its lower legs, and with the pelvises of two red deer (perhaps meat offerings) by its shoulder and its feet. Round its neck was a perforated-shell pendant, and on its forehead was some kind of headdress made up of four canine teeth from two different red-deer stags and two hinds. This burial can therefore be grouped with roughly similar Gravettian ochre burials known in Britain (at Paviland), Russia (Sungir) and especially Moravia.

Most of the book - no less than 275 pages - is devoted to an exhaustive inventory of the human bones and teeth, making available to the scientific community all of the morphological details and measurements. Different methods of determining dental age at death give a mean age of 4.7 years, and the skeletal age at death corresponds with this assessment.

From the start it was clear that this was an anatomically modern child - it has a chin and other modern features - but the bodily proportions, especially those of the legs, suggest some Neanderthal input. This claim led to an academic furore that smacked more of an argument based on emotion and entrenched beliefs than of an open-minded, cold and logical debate.
This monograph should go a long way towards resolving the issue, although those with extreme opinions are unlikely to be swayed. The data seem to have been provided as objectively as possible; for example, the morphology of the child's bony labyrinth (inner ear) points to it being a modern human, yet the authors of that section say that their data are inconclusive with regard to the hybrid theory.

Overall, the Lapedo child is clearly not a normal anatomically modern human, and it displays an unusual mosaic of postcranial characteristics - especially in the lower limbs, but also in some features of the upper ones. It also has a pitting of the occipital bone in the skull, which some specialists consider virtually diagnostic of Neanderthals.

The editors (who are also the principal investigators of the child) do consider possible alternative explanations - such as nutritional or climatic factors - for the child's unusual proportions. But they conclude that no alternative hypothesis has yet been presented that fits the data better than their hybridization theory.

The book ends with some remarkable and useful surveys of Neanderthal and early Upper Palaeolithic burials of different kinds, and of the whole contentious issue of the Middle-to-Upper Palaeolithic transition. Most readers, however, will probably only want to know if this is just a "chunky modern kid", as it has sometimes been described, or whether it is really a hybrid of Neanderthals and Cro-Magnons. The question remains open, and the editors have taken pains to present all the data, which others can use to form an opinion, while arguing very persuasively in favour of their own view.

What's crucial is that the issue should be presented accurately. This is emphatically not a question of whether any evidence of Neanderthal ancestry can be found in present-day Europeans, but of whether such evidence can be found in early Upper Palaeolithic Europeans. The much-touted DNA analyses carried out in recent years on a few Neanderthal bones are therefore of no consequence here whatsoever. Nobody is claiming Neanderthal genetic continuity to the present day descendants are irrelevant, and in any case this child almost certainly had none. It is a question of ancestry, and, faced with the evidence assembled here, it is hard to deny the strong possibility that this child could indeed have had mixed antecedents.

Paul G. Bahn is the consultant editor of Written in Bones (Firefly, \$35 ( $h b k$ ), $\$ 24.95(p b k))$. 